\title{
ANALISIS PRODUKTIVITAS PENGEBORAN TANAH MENGGUNAKAN ALAT RCD (REVERSE CIRCULATION DRILLING)
}

\author{
Kusumo Drajad Sutjahjo ${ }^{1}$, Tri Wulan $\operatorname{Sari}^{2}$, Ghaisani Husna Hawari ${ }^{3}$ \\ Jurusan Teknik Sipil 123 \\ Politeknik Negeri Jakarta \\ Jl. Prof. DR. G.A. Siwabessy, Kampus Universitas Indonesia, Kota Depok, Jawa Barat \\ Email: kusumo.drajadsutjahjo@sipil.pnj.ac.id; tri.wulansari@sipil.pnj.ac.id; ghaisanihh@gmail.com
}

\begin{abstract}
Abstrak
Proyek Kereta Cepat Jakarta Bandung merupakan mega proyek kereta cepat pertama di Indonesia. Kondisi tanah terdapat batu cadas yang keras, alat yang sudah tua dengan pemakaian yang terus menerus menyebabkan mesin mati tiba - tiba dan jenis tanah yang menjadi lengket bila bertemu dengan air yang dapat memperlambat proses pengeboran tanah. Berbagai cara pekerjaan pengeboran tanah dilakukan oleh kontraktor, salah satunya menggunakan alat RCD pada pier P 238. Tujuan dari karya ilmiah ini menganalisis produktivitaspengeboran tanah dengan menggunakan alat RCD. Langkah pengeboran dimulai dari pembersihan lapangan dan pembuatan dua buah kolam. Untuk mempermudah pengeboran tiang bor digunakanlah casing. Tinggi casing yang digunakan $4 \mathrm{~m}$ dan $6 \mathrm{~m}$. Setelah itu melakukan pengeboran dengan tekanan air $0,2 \mathrm{Kg} / \mathrm{cm} 2$ atau dengan kecepatan aliran 7,5 cm/detik sehingga air akan keluar bersama dengan material lumpur melalui pipa di tengah alat bor. Hasil endapan lumpur (padatan) akan dibuang menggunakan truck sedangkan cairan akan dimasukan kembali kedalam lubang bor. Pruduktivitas alat bergantung pada empat faktor yaitu volume pekerjaan, waktu siklus, efisiensi alat dan kapasitas peoduksi. Pada pier 238 memiliki 8 borepile dengan diameter 1,25 meter dan kedalaman 90 meter dengan rata - rata produktivitas sebesar $2,851 \mathrm{~m} / \mathrm{jam}$.
\end{abstract}

Kata kunci :

Tiang bor; Produktivitas; RCD.

\begin{abstract}
The Jakarta Bandung Fast Train Project is the first mega fast train project in Indonesia. Soil conditions are hard rock, old tools with continuous use cause the engine to shut down suddenly and the type of soil becomes sticky when it meets water which can slow down the soil drilling process. Contractors have carried out various ways of drilling soil, one of which is using an RCD tool on pier P 238. The purpose of this scientific paper is to analyze the productivity of soil drilling using an RCD tool. The drilling step starts from cleaning the field and making two ponds. To simplify the drilling of the drill pile a casing is used. The height of the casing used is $4 \mathrm{~m}$ and $6 \mathrm{~m}$. After that, drill with water pressure of $0.2 \mathrm{Kg} / \mathrm{cm} 2$ or with a flow rate of $7.5 \mathrm{~cm} /$ second so that the water will come out along with the mud material through the pipe in the middle of the drill tool. The resulting silt (solids) will be disposed of using a truck while the liquid will be fed back into the borehole. Tool productivity depends on four factors, namely the volume of work, cycle time, efficiency of the tool and production capacity. Pier 238 has 8 borepiles with a diameter of 1.25 meters and a depth of 90 meters with an average productivity of $2.851 \mathrm{~m} /$ hour.
\end{abstract}

Keywords :

Bore pile; Productivity; RCD.

\section{Pendahuluan}

Salah satu alat pengeboran yang digunakan dalam Proyek Kereta Cepat Jakarta - Bandung adalah RCD (Reverse Circulation Drilling). Metode RCD ini sudah pernah diterapkan pada saat 
Pembangunan Jembatan Holtekamp Jayapura(Umum, 2017). Kereta Cepat Jakarta Bandung dibangun pada jalur jembatan layang atau elevated, dan di atas tanah yang di antaranya melalui tunnel atau terowongan yang menembus bukit. Kondisi tanah pada daerah tersebut rawan atau labil karena terdapat batu cadas yang keras, tanah yang padat, dan jenis tanah yang menjadi lengket bila bertemu dengan air dapat memperlambat proses pengeboran tanah. Oleh karena itu, artikel ini akan membahas mengenai analisis produktivitas pengeboran tanah dengan menggunakan alat RCD. Persiapan alat untuk pengeboran RCD meliputi : Mesin RCD, Mata Bor RCD, Pipa Bor, Spul Balk, dan Compressor(Umum, 2017). Langkah pengeboran dimulai dari pembersihan lapangan dan pembuatan dua buah kolam. Untuk mempermudah pengeboran tiang bor digunakanlah casing. Tinggi casing yang digunakan $4 \mathrm{~m}$ dan $6 \mathrm{~m}$. Setelah itu melakukan pengeboran dengan tekanan air $0,2 \mathrm{Kg} / \mathrm{cm} 2$ atau dengan kecepatan aliran 7,5 cm/detik sehingga air akan keluar bersama dengan material lumpur melalui pipa di tengah alat bor(Umum, 2017). Hasil endapan lumpur (padatan) akan dibuang menggunakan truck sedangkan cairan akan dimasukan kembali kedalam lubang bor(Sokop et al., 2018).

Produktivitas alat merupakan kemampuan alat dalam satuan waktu. Produktivitas alat bergantung pada empat faktor yaitu volume pekerjaan, waktu siklus, efisiensi alat dan kapasitas produksi(Dian Febrianti \& Zakia, 2018; Sutanto et al., 2017). Volume pekerjaan adalah jumlah kapasitas pekerjaan yang harus diselesaikan dalam setiap pekerjaan. Waktu siklus merupakan waktu yang diperlukan alat berat untuk melakukan satu siklus operasi(Jaya \& Sutandi, 2019).

Setiap alat memiliki cara tertentu untuk menghitung waktu siklus yang bergantung pada pengoperasian masing-masing alat(Jaya \& Sutandi, 2019). Langkah pengeboran dimulai dari pembersihan lapangan dan pembuatan dua buah kolam. Pembuatan casing dilakukan untuk mempermudah pengeboran tiang dan menghindari terjadinya kelongsoran tanah. Tinggi casing yang digunakan $4 \mathrm{~m}$ dan $6 \mathrm{~m}$. Setelah itu melakukan pengeboran dengan tekanan air $0,2 \mathrm{Kg} / \mathrm{cm} 2$ atau dengan kecepatan aliran 7,5 cm/detik sehingga air akan keluar bersama dengan material lumpur melalui pipa di tengah alat bor(Umum, 2017). Waktu siklus pengeboran dapat dirumuskan seperti pada persamaan $\mathrm{Ts}=\mathrm{T} 1+\mathrm{T} 2$ dengan $\mathrm{Ts}$ adalah waktu siklus, T1 adalah lama waktu pemasangan casing dan T2 adalah waktu pengeboran. Pada pier 238 memiliki 8 borepile dengan diameter 1,25 meter dan kedalaman 90 meter dengan rata - rata produktivitas sebesar 2,851 m/jam(Umum, 2017).

Proyek konstruksi dapat diartikan sebagai rangkaian kegiatan yang saling berkaitan untuk mencapai tujuan yaitu bangunan/konstruksi dalam batasan waktu, biaya dan mutu tertentu. Hal yang pasti diperlukan dalam proyek konstruksi antara lain; resources (sumber daya) yaitu man (manusia), material (bahan bangunan), machine (peralatan), method (metode pelaksanaan), money (uang), information (informasi), dan time (waktu)(I Wayan Jawat et al., 2020). Saat melakukan operasi pengeboran dan peledakan dipengaruhi oleh beberapa faktor antara lain; kecepatan pengeboran, efisiensi pemboran, geometri peledakan, fragmentasi batuan, dan sebagainya. Parameter yang bisa menghambat operasi pengeboran dan peledakan harus dihindaari semaksimal mungkin. Kegiatan pengeboran dikatakan baik jika sesuai dengan geometri yang telah direncanakan dan menghasilkan fragmentasi hasil peledakan sesuai dengan yang diharapkan(Purwandanu et al., 2019).

\section{KAJIAN LITERATUR}

Penelitian terdahulu pada tahun 2014 yang dilakukan oleh Aditya Dhiva menyimpulkan bahwa faktor-faktor yang mempengaruhi produktivitas pengeboran antara lain:

a. Mesin bor pile ringan yang digunakan pada metode direct wash yaitu: kekerasan tanah, diameter lubang bor, kedalaman pengeboran, medan kerja, letak sumber air, daya mesin, cuaca, tenaga kerja, dan beberapa faktor lainnya;

b. Faktor yang paling berpengaruh pada produktivitas pengeboran pondasi terdiri dari 4 faktor, antara lain; kekerasan tanah (X1.2), daya mesin (X4.1), diameter (X6.1) dan kedalaman pengeboran (X6.2). Hasil pengujian korelasi antara variabel bebas dengan variabel terikat (produktivitas pengeboran) menunjukkan bahwa variabel bebas mempengaruhi variabel terikat secara signifikan dengan level of significance 5\%.

Kusumo Drajad Sutjahjo, Tri Wulan Sari, Ghaisani Husna Hawari 
c. Pengujian model yang terbentuk dengan menggunakan beberapa tool pengujian statistik menjelaskan bahwa secara statistik model yang dilakukan dapat menunjukkan hubungan antara variabel bebas terhadap variabel terikat (Dhiva, 2014).

Penelitian lain yang telah dilakukan oleh Lesmana et. al. pada tahun 2015 menyimpulkan bahwa produktivitas dan analisa pengaruh faktorfaktor penghambat yang muncul di lapangan antara lain: Pada proyek PRAXIS selama 40 hari penelitian dengan total 1653 jam kerja,

a. rata-rata produktivitas tiang bored pile setiap alat sebesar 3,84 m/hour.

b. faktor equipment mempunyai pengaruh yang terbesar di dalam menurunkan tingkat produktivitas pekerjaan pondasi bored pile yang tercermin pada besarnya kehilangan jam kerja atau workhours lost yaitu sebesar 83,37 jam (40,39\%) dari total workhours lost sebesar 206,41 jam .

c. Faktor-faktor lain yang juga menurunkan produktivitas pekerjaan pondasi bored pile adalah environtment (5,52 jam;2,68\%), labor $(63,3 \mathrm{jam} ; 30,66 \%)$, material $(4,77 \mathrm{jam}$; $2,31 \%)$, dan management $(49,46$ jam; 23,96\%)(Lesmana \& Alifen, 2015).

Penelitian terdahulu yang lainnya jenis alat bor Furukawa HCR 1500-ED menggunakan 3 steel dengan kemampuan pemboran yaitu 32 lubang ledak/hari dengan kecepatan pemboran 1,51 meter/menit, efisiensi kerja alat bor $76,73 \%$, ketersediaan alat (PA) 84,99\%, efesiensi mekanis (MA) 85,31\%, efesiensi pemakaian alat (UA) 90,23 $\%$, dan efesiensi waktu kerja (EU) 76,73\%. Dari hasil tersebut belum memenuhi atau mendukung target produksi pemboran secara keseluruhan, dimana target produksinya yaitu 40-50 lubang ledal/hari (Supratman et al., 2017).

\section{Analisis dan Perancangan}

Pondasi tiang bor adalah pondasi yang dipasang kedalam tanah dengan cara mengebor tanah terlebih dahulu, baru kemudian diisi dengan tulangan dan dicor beton(Isnaniati, 2013). Lokasi penelitian berada pada Proyek Kereta Cepat Jakarta - Bandung Seksi IV di DK 138. Proyek Kereta Cepat Jakarta Bandung terbentang dari Halim Perdana Kusuma, Jakarta Timur - Tegalluar (seberang Gede Bage) di Bandung, Jawa Barat yang memiliki panjang 142,3 $\mathrm{km}$ [4]. Penelitian ini menggunakan alat pengeboran
$R C D$ adalah struktur pier $\mathrm{P} 238$ dengan diameter 1,25 meter dan kedalaman 90 meter. Langkah pengeboran seperti yang terlihat pada Gambar 1, yaitu dimulai dari pembersihan lapangan dan pembuatan dua buah kolam. Untuk mempermudah pengeboran tiang bor digunakan casing. Tinggi casing yang digunakan $4 \mathrm{~m}$ dan $6 \mathrm{~m}$. Setelah itu melakukan pengeboran dengan tekanan air $0,2 \mathrm{Kg} / \mathrm{cm} 2$ atau dengan kecepatan aliran $7,5 \mathrm{~cm} /$ detik sehingga air akan keluar bersama dengan material lumpur melalui pipa di tengah alat bor [1] Hasil endapan lumpur (padatan) akan dibuang menggunakan truck sedangkan cairan akan dimasukan kembali kedalam lubang bor. Metode pengumpulan data yang dipakai oleh penulis adalah metode wawancara kepada pelaksana. Data yang diperlukan untuk menghitung produktivitas alat yaitu mengetahui waktu siklus pada masing - masing borepile. Pada table 1 digambarkan waktu siklus pada alat $R C D$ pier P 238 dengan kode titik dan waktu siklus 1 sampai dengan 8 .

Tabel 1 Waktu siklus pada alat RCD pier $\mathrm{P} 238$

\begin{tabular}{cc}
\hline Kode Titik & Waktu Siklus (menit) \\
\hline 1 & 1474 \\
2 & 1452 \\
3 & 1650 \\
4 & 1495 \\
5 & 1514 \\
6 & 1183 \\
7 & 1232 \\
8 & 1489 \\
\hline
\end{tabular}

Diagram alir langkah - langkah pengeboran menggunakan Alat $R C D$ adalah sebagai berikut

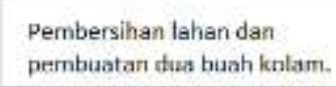

pernbuatan dua buah knlam.

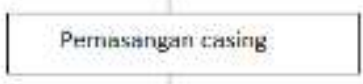

Melakukan Perigeburan iderigan tckonan air $0,2 \mathrm{Kg} / \mathrm{cm} 2$

Melakukan perhitungan produktivitas alat RCD

Gambar 1. Langkah Pengeboran dengan menggunakan alat $R C D$

Produktivitas merupakan perbandingan antara hasil yang dicapai (output) dengan seluruh sumber daya yang digunakan (input)(Sutanto et al., 2017).

Kusumo Drajad Sutjahjo, Tri Wulan Sari, Ghaisani Husna Hawari 
Produktivitas alat tergantung pada kapasitas dan waktu siklus alat [5]. Pada umumnya waktu siklus alat ditetapkan dalam menit sedangkan produktivitas alat dihitung dalam produksi/jam sehingga perlu ada perubahan dari menit ke jam. Jika faktor efisiensi alat diperoleh rumus secara matematika sebagai berikut:

$$
Q=\frac{\mathrm{V} \cdot \mathrm{p} \cdot 60 \cdot \mathrm{Fa}}{\mathrm{Ts}}
$$

Keterangan:

$\mathrm{Q}=$ Kapasitas produksi (m/jam)

$\mathrm{V}=$ Kapasitas alat atau volume pekerjaan (titik)

$\mathrm{P} \quad=$ Panjang pengeboran dalam satu titik (m)

$\mathrm{Fa}=$ Faktor efisiensi alat

Ts = Waktu siklus pengeboran (menit)

(Microsoft, 2021)

Waktu siklus alat $R C D$ masing - masing bore pile pada Tabel 1, dapat dihitung produktivitas alat yang dipakai dengan menggunakan perhitungan yang jalan menghitungnya sesuai dengan saat mengikuti mata kuliah Fisika Terapan untuk Teknik Sipil sebagai berikut

1. Waktu siklus 1474 menit

Diketahui :

1) Faktor Efisiensi Alat $(\mathrm{Fa}) \quad=0,75$

2) Waktu Siklus (Ts) = 1474 menit

3) Kedalaman Lubang Bor (p) $=90 \mathrm{~m}$

\section{Ditanya :}

Produktivitas alat/Jam (Q)

Answer :

$$
\begin{gathered}
Q=\frac{\mathrm{V} \cdot \mathrm{p} \cdot 60 \cdot \mathrm{Fa}}{\mathrm{Ts}}=\frac{1 \cdot 90 \cdot 60 \cdot 0,75}{1474} \\
=2,75 \mathrm{~m} / \mathrm{jam}
\end{gathered}
$$

Jadi produktivitas yang dihasilkan alat RCD dengan waktu siklus 1474 menit sebesar $2,75 \mathrm{~m} / \mathrm{jam}$.

2. Waktu siklus 1452 menit

Diketahui :
1) Faktor Efisiensi Alat $(\mathrm{Fa}) \quad=0,75$

2) Waktu Siklus (Ts) = 1452 menit

3) Kedalaman Lubang Bor (p) $=90 \mathrm{~m}$

Ditanya :

Produktivitas alat/Jam (Q)

Answer :

$$
\begin{aligned}
Q=\frac{\mathrm{V} \cdot \mathrm{p} .60 \cdot \mathrm{Fa}}{\mathrm{Ts}} & =\frac{1 \cdot 90 \cdot 60 \cdot 0,75}{1452} \\
& =2,79 \mathrm{~m} / \mathrm{jam}
\end{aligned}
$$

Jadi produktivitas yang dihasilkan alat $R C D$ dengan waktu siklus 1452 menit sebesar $2,79 \mathrm{~m} / \mathrm{jam}$.

3. Waktu siklus 1650 menit

Diketahui :

1) Faktor Efisiensi Alat $(\mathrm{Fa}) \quad=0,75$

2) Waktu Siklus (Ts) = 1650 menit

3) Kedalaman Lubang Bor (p) $=90 \mathrm{~m}$

Ditanya :

Produktivitas alat/Jam (Q)

Answer :

$$
\begin{gathered}
Q=\frac{\mathrm{V} \cdot \mathrm{p} \cdot 60 \cdot \mathrm{Fa}}{\text { Ts }}=\frac{1 \cdot 90 \cdot 60 \cdot 0,75}{1650} \\
=2,45 \mathrm{~m} / \mathrm{jam}
\end{gathered}
$$

Jadi produktivitas yang dihasilkan alat $R C D$ dengan waktu siklus 1650 menit sebesar 2,45 m/jam.

4. Waktu siklus 1495 menit

Diketahui :

1) Faktor Efisiensi Alat $(\mathrm{Fa}) \quad=0,75$

2) Waktu Siklus (Ts) = 1495 menit

3) Kedalaman Lubang Bor (p) $=90 \mathrm{~m}$

\section{Ditanya :}

Produktivitas alat/Jam (Q)

Answer :

$$
\begin{gathered}
Q=\frac{\mathrm{V} \cdot \mathrm{p} \cdot 60 \cdot \mathrm{Fa}}{\mathrm{Ts}}=\frac{1 \cdot 90 \cdot 60 \cdot 0,75}{1495} \\
=2,71 \mathrm{~m} / \mathrm{jam}
\end{gathered}
$$


Jadi produktivitas yang dihasilkan alat $R C D$ dengan waktu siklus 1495 menit sebesar $2,71 \mathrm{~m} / \mathrm{jam}$.

5. Waktu siklus 1514 menit

Diketahui :

1) Faktor Efisiensi Alat $(\mathrm{Fa}) \quad=0,75$

2) Waktu Siklus (Ts) = 1514 menit

3) Kedalaman Lubang Bor (p) $=90 \mathrm{~m}$

\section{Ditanya :}

Produktivitas alat/Jam (Q)

Answer :

$$
\begin{gathered}
Q=\frac{\text { V. p } .60 \cdot \mathrm{Fa}}{\text { Ts }}=\frac{1 \cdot 90 \cdot 60 \cdot 0,75}{1514} \\
=2,68 \mathrm{~m} / \mathrm{jam}
\end{gathered}
$$

Jadi produktivitas yang dihasilkan alat $R C D$ dengan waktu siklus 1514 menit sebesar $2,68 \mathrm{~m} / \mathrm{jam}$.

6. Waktu siklus 1183 menit

\section{Diketahui :}

1) Faktor Efisiensi Alat $(\mathrm{Fa}) \quad=0,75$

2) Waktu Siklus (Ts) = 1183 menit

3) Kedalaman Lubang Bor (p)=90 m

\section{Ditanya :}

Produktivitas alat/Jam (Q)

Answer :

$$
\begin{gathered}
Q=\frac{\text { V. p } .60 \cdot \mathrm{Fa}}{\text { Ts }}=\frac{1 \cdot 90 \cdot 60 \cdot 0,75}{1183} \\
=3,42 \mathrm{~m} / \mathrm{jam}
\end{gathered}
$$

Jadi produktivitas yang dihasilkan alat $R C D$ dengan waktu siklus 1183 menit sebesar 3,42 m/jam.

7. Waktu siklus 1232 menit

Diketahui :

1) Faktor Efisiensi Alat $(\mathrm{Fa}) \quad=0,75$

2) Waktu Siklus (Ts) = 1232 menit

3) Kedalaman Lubang Bor (p) $=90 \mathrm{~m}$

\section{Ditanya :}

Produktivitas alat/Jam (Q)

Answer :

$$
\begin{gathered}
Q=\frac{\text { V. p } \cdot 60 \cdot \mathrm{Fa}}{\text { Ts }}=\frac{1 \cdot 90 \cdot 60 \cdot 0,75}{1232} \\
=3,29 \mathrm{~m} / \mathrm{jam}
\end{gathered}
$$

Jadi produktivitas yang dihasilkan alat $R C D$ dengan waktu siklus 1232 menit sebesar 3,29 m/jam.

8. Waktu siklus 1489 menit

\section{Diketahui :}

1) Faktor Efisiensi Alat $(\mathrm{Fa}) \quad=0,75$

2) Waktu Siklus (Ts) = 1489 menit

3) Kedalaman Lubang Bor (p) $=90 \mathrm{~m}$

\section{Ditanya :}

4) Produktivitas alat/Jam (Q)

Answer :

$$
\begin{gathered}
Q=\frac{\text { V. p } .60 \cdot \mathrm{Fa}}{\text { Ts }}=\frac{1 \cdot 90 \cdot 60 \cdot 0,75}{1489} \\
=2,72 \mathrm{~m} / \mathrm{jam}
\end{gathered}
$$

Jadi produktivitas yang dihasilkan alat $R C D$ dengan waktu siklus 1489 menit sebesar $2,72 \mathrm{~m} / \mathrm{jam}$.

Dari analisis data pada perhitungan di atas dapat dilihat bahwa masing - masing waktu siklus memiliki produktivitas yang berbeda. Hubungan antara waktu siklus dan produktivitas adalah berbanding terbalik, yaitu semakin tinggi waktu siklus alat RCD pier $\mathrm{P} 238$ produktivitas yang dilakukan alat semakin kecil.

Perhitungan produktivitas dengan waktu siklus 1-8 di atas dapat dihitung Rata - rata produktivitas alat RCD pier $\mathrm{P} 238$ yaitu

$$
\begin{aligned}
& \mathrm{Q}_{1}+\mathrm{Q}_{2}+\mathrm{Q}_{3}+\mathrm{Q}_{4}+\mathrm{Q}_{5}+\mathrm{Q}_{6}+\mathrm{Q}_{7}+\mathrm{Q}_{8} / 8 \\
& =(2,75+2,79+2,45+2,71+2,68+3,42+ \\
& 3,29+2,72) / 8 \\
& =2,85 \mathrm{~m} / \mathrm{jam} .[6]
\end{aligned}
$$

Sehingga produktivitas rata - rata yang mampu dilakukan alat RCD pier $\mathrm{P} 238$ adalah 2,85 m/jam.

Kusumo Drajad Sutjahjo, Tri Wulan Sari, Ghaisani Husna Hawari 


\section{KESIMPULAN DAN SARAN}

Alat RCD pier P 238 yang digunakan untuk pengeboran tanah pada Proyek Kereta Cepat Jakarta Bandung dengan diameter 1,25 meter dan kedalaman lubang bor 90 meter memiliki rata-rata produktivitas sebesar 2,85 $\mathrm{m} / \mathrm{jam}$, sehingga diharapkan produktivitas ini mampu membantu perekomendasian alat yang digunakan untuk pengeboran kawasan proyek kereta cepat Jakarta Bandung.

\section{REFERENSI}

Dhiva, I. G. N. A. (2014). Analisis Produktivitas Pengeboran Pondasi Bor Pile dengan Menggunakan Mesin Bor Ringan. Jurnal Rekayasa Sipil, 8(2), 128-135. https://rekayasasipil.ub.ac.id/index.php/rs/articl e/view/276

Dian Febrianti, \& Zakia. (2018). Analisis produktivitas dan waktu penggunaan alat berat excavator pada pekerjaan galian tanah 12 2). Prosiding Seminar Nasional Paker Ke 1, 1, 123-127.

I Wayan Jawat, Putu Panji Tresna Gita, \& I Made Satria Dharmayoga. (2020). Kajian Metoda Pelaksanaan Pekerjaan Pondasi Bored Pile Pada Tahap Perencanaan Pelaksanaan. PADURAKSA: Jurnal Teknik Sipil Universitas Warmadewa, 9(2), 126-142. https://doi.org/10.22225/pd.9.2.1830.126-142

Isnaniati. (2013). Pengaruh Penggunaan Tiang Bor dan Tiang Pancang Terhadap Besarnya Penurunan Konsolidasi Pada Tanah Lempung. Prosiding: Seminar Nasional III Teknik Sipil 2013 Universitas Muhammadiyah Surakarta, 3(1), 331-338.

Jaya, W., \& Sutandi, A. (2019). Analisis Produktivitas Alat Berat Mesin Bor Auger, Crawler Crane, Dan Excavator Pada Proyek a Dan B. JMTS: Jurnal Mitra Teknik Sipil, 2(1), 11. https://doi.org/10.24912/jmts.v2i1.3030

Lesmana, A. P., \& Alifen, R. S. (2015). Analisis Produktivitas Pekerjaan Pondasi Bored Pile ( Studi Kasus Pada Bangunan Perkantoran 31 Lantai ). 1-7.

Microsoft. (2021). Menghitung rata-rata grup angka.
Purwandanu, A. E., Toha, M. T., \& Bochori. (2019). Parameter yang Mempengaruhi Produktivitas Pengeboran, Peledakan, dan Sistem ShovelDump Truck pada Tambang Andesit. Pertambangan, 5(4), 23-27. http://ejournal.ft.unsri.ac.id/index.php/JP

Sokop, R. M., Arsjad, T. T., Malingkas, G., Sipil, T., Sam, U., Manado, R., Manado, J. K. B., \& Belakang, A. L. (2018). Analisa Perhitungan Produktivitas Alat Berat Gali-Muat (Excavator) Dan Alat Angkut (Dump Truck) Pada Pekerjaan Pematangan Lahan Perumahan Residence Jordan Sea. Tekno, 16(70), 83-88.

Supratman, Anshariah, \& Bakri, H. (2017). Produktivitas Kinerja Mesin Bor Dalam Pembuatan Lubang Ledak Di Quarry Batugamping B6 Kabupaten Pangkep Propinsi Sulawesi Selatan. Jurnal Geomine, 5(2), 59-63. https://doi.org/10.33536/jg.v5i2.127

Sutanto, K. R., Kosasi, M. H., \& Andi. (2017). Produktivitas Alat Berat pada Pekerjaan Galian Gedung P1 P2 UK Petra. Jurnal Universitas Kristen Petra, 1-8. https://www.skyscrapercity.com/showthread.ph $\mathrm{p} ? \mathrm{t}=2040313$

Umum, K. P. (2017). Penerapan Teknologi Konstruksi. 